\title{
Nursing Guidelines and Its Effects on Nurses' Knowledge and Patient Safety Regarding Nosocomial Infection Control Measures in Burn Unit
}

\author{
Salwa A. Mohammed \\ AssistProfessor of Medical Surgical Nursing Department, Faculty of Nursing, Fayoum University, Egypt \\ Correspondence: Salwa A. Mohamed. Address: Faculty of Nursing, Fayoum University, Egypt. \\ Email:sam15@fayoum.edu.eg
}

\begin{abstract}
:
Background:Infection prevention and control (IPC) is core components of patient safety, as hospital acquired infection is the most common complication affecting hospitalized patients. The aim of the present study is to evaluate effects of implementing nursing guidelines on nurses' knowledge and patient's safety regarding nosocomial infection control measures in burn unit.

Methods:Quasi-experimental design was utilized.A study ofconvenience sample(35 nurses and 40 patients) from Burn Department (BD) at Public Fayoum. Four tools were utilized to collect data related to this study: demographic variables for subject study, nosocomial infection questionnaires and observational checklist for nurse performance and patientobservational for sign and symptoms of infection.

Results:The finding of this study exposed that: (a) A significant statistical improved of nurses knowledge score after implementation of nursing guidelines program. (b) There were a high statistical significant difference between nurses' knowledge and practice. (d) There were improved safety burn patients as evidence by fewer incidences of signs and symptoms of infection among study group after implementation of program.

Conclusion:This study exposed that improvement of nursing staffs' knowledge and practice regarding nosocomial prevention and control. Also decrease signs and symptoms of infection among patient lead to improve outcome amd promote patient safety.
\end{abstract}

Recommendations: The current study recommended that continues education program related to nosocomial infection and patient safety for nursing staff in this area.

Keyword:Nosocomial infection, nursing guideline, patient safety, burn injury

\section{Introduction}

Burns have always been considered asone of the most destructive injuries between people of all age and one of thirty leading causes worldwide of lack of life years due to premature mortality and disabilitythat persists long after injury (Rajpura, 2002; Kidal, 2003). Burn can experience with devastating effects on the skin or other organic tissue in the body. Burn injury occurs from tissue loss or tissue damage, as a result of direct contact or exposure to any heat, radiation, electricity, or chemicals (O'Keeffe, hunt, \& Purdue, 2001; Karim \& Edward, 2011;Lewis, et al., 2014). The severity of a burn depends on the depth of tissue damage and the body surface affected. It is intended to emphasize the importance of making a comprehensive assessment rapid and comprehensive of those who suffer this type of injury and to act immediately to meet the needs and its complications (D'Souza, et al., 2009).

Infection complication in the burn patient emerges as the leading cause of morbidity and mortality and continuous to be one of the greatest challenging concerns for the burn team. Burn patients are at a considerable risk for infection because the burn injury itself, suppressed immune systemdue to burn, lengthy hospital stays and therapeutic procedures (Plowman et al., 2001). Changes in that preservation determine the patient's susceptibility to infection. So prevention and management of infection is a primary concern in the treatment of burn patients. This was included strict aseptic techniques, proper use of personal protective equipment's and proper hand washing(Hospenthal, Green, Crouch, et al. 2011).

Nosocomial infections(NIs) are considered to be the most common complication affecting hospitalized human patients, and this infection consideredare the eighth leading cause of death in the United States (Wenzel \& Edmond, 2001; Burke, 2003).A study done by study done by Tancheva (2002) detected that approximately $73 \%$ of all deaths through the initial 5 day post-burn have been caused by septic processes.

Nosocomial infections are associated with increased length of stay, prolonged therapy as well as to excess cost for hospitalized patients. Infection occurring more than 48 hours after admission is usually considered nosocomial (Ahmed, Daef, Badary, Mahmoud, and Abd-Elsayed, 2009 and Kenetra, 
2013). Therefore, control and prevention of infectious diseases among burned patients present a greater and can help reduce the incidence(Curtis, 2008 and Szucs, et al., 2014). In addition, the most important factor in minimizing nosocomial infections is improving the hand hygiene of health care providers can dramatically reduce the transmission of bacteria between patients. Also the promotion of aseptic technique should be used in everyday part of patient care and management of all invasive devices(Johanson, 2002).

Patient safety is a serious global public health issue. The estimation shows that in developed countries as many as one in 10 patients is harmed while receiving hospital care. Also, approximately 1.4 million people worldwide are prone to infections acquired in hospitalsat any given time.In addition, every point in the process of care-giving contains a certain degree of inherent unsafety. Patient safety is an essential part of nursing care that aims to prevent avoidable errors and patient harm. Therefore, encouraging hospitals and healthcare facilities to apply evidence-based recommendations to maximize prevention efforts and contribute to a greater awareness and understanding of the importance of hand hygiene. These are a continuous opportunity to improve and maximize patient safety (Larson, 1999; Weinstein 2001 and Canadian Council on Health Services, 2005).

Prevention of healthcare-associated infections is the responsibility of all healthcare personnel. Nurses have greatest role to prevent the transmission of nosocomial infections among patients and protecting the health of the staff(Taylor, Lillis \& LeMone, 2005). Infection prevention and control is an integral component of nursing care delivery in any setting to reduce risks for mortality and morbidity in patients. Education of staff members regarding early detection,risks and symptoms associated with nasocomail infection, infection control, and effective hand hygiene are key elements to consider(Johanson, 2002).In addition, nursing personal can reduce the risk of infection by proper hand hygiene and proper use of personal protective barriers when changed wound dressing and any invasive procedure for patients care (Gill 2005).

\section{Operational definition:}

Nursing Guidelines: It is a designated program provided to burn nurses and patients to improve their knowledge, performance with procedure among staff and clinical outcomes.

Patient safety:Comprise procedure that protect patients from nosocomial infection such as hand hygiene, use personal protective equipment, and promote environmental control are proper strategies for preventing nosocomial infection and improved health quality care.

Significance of the Study:

Nosocomial infections (NI) are the most common complication of hospital care and major problem worldwide and pretend a severe threat to the lives and integrity of patients who convene them. Persistent processes of fight these infections are of great importance because of the high economic cost and high morbidity and mortality rates associated with these infections(Kenetra, 2013).There are many people who require urinary catheters, blood transfusion, and wound dressing in order to receive much needed antibiotics. Prevention and management of infection is the responsibility of all staff working in health care, and an integral element of patient safety.

Infection control nurses play an important role in burn unit. Subsequently, assessment level of nurses' knowledge and practice about infection control technique is vital action to control infection in the burn unit. Patient who admitted burn unit usually are highly susceptible to infection. Thus, the application of universal precautions protected staff, patients and environment from infection it is restricted uses in burn unit to promote patient safety and decrease risk.

\section{Aim of the Study}

This study aimed to evaluate effects of implementing nursing guidelines on nurse's knowledge and patient's safety regarding nosocomial infection control measures in burn unit.

\section{Research hypothesis:}

H1: Nurses will have better knowledge about nosocomial infection in burn unit after implementation of nursing guidelines.

H2: The nurses will give better practice for the patient regarding nosocomial infection pre, immediately and after implementing program.

H3: The patient's signs and symptoms of nosocomial infection will be decline after implementation of teaching guidelines.

\section{Material: \\ Research design and setting:}

Quasi-experimental design was utilized in carrying out to the study. The study was conducted in burn unit at Fayoum public hospitals.

Study Subjects: 
Nurses:The subjects of the study consists of all the nurses working in burn unit at Public Fayoum Hospitals, and those providing care for patients undergoing burn care. The total number of the studies nurses was 35 nurses. The criteria for selection were, all nurses who are willing to participate, with any age and different levels of education, and different years of experiences. The subjects with chronic infection were excluded.

Patients: The total numbers of patient's 40 patients admitted at burn unit, patients' age between 18-60 years old and agreeing to participate in the research.

Tools:

It consists of the following:

Part 1: Socio-demographic and Medical data:

Tools for nurse:

Two types of tools were used for collection of data. It included a socio-demographic sheet and an observational checklist.

Tool I: Socio-demographic data sheet: It was developed to assess socio-demographic characteristics of nurses such as age, education, occupation, and experience in burn unit.

\section{Tool II: Burn Knowledge Questionnaire:}

A Questionnaire sheet was prepared for the purpose of assessment of nurses' knowledge regarding infection control measures. It was elicited from the review of related literature and constructed by the researcher in Arabic form. It consists of 94 questions divided into parts: knowledge about infection; nosocomial infection and general measures to control infection(22 questions); disinfection and sterilization (14 questions); hand washing ( 7 questions); urinary tract infection and its measures (12 questions); respiratory tract infection(19 questions); blood steam infection and its control measures (16 questions) and (3) questions about surgical sites infection.

\section{Scoring System:}

The nurses' knowledge was given scores according to its weight and importance:one for correct answer and zero for incorrect answer. For each areas of knowledge, the scores of each subject were summed up, and converted into a percent total score. Rating scale of all questions was collected. Total score was 94 grades and high scoreis good practice.

\section{Part III: Observational Checklist Sheet:}

A clinical observational checklist was constructed based on the literature nursing review (Smeltzer $\&$ Bare, 2000; Taylor et al., 2001). It was performed during morning and afternoon shifts. The checklist was required to monitor the compliance of nurses for infection control measures at burn unit. It contains of 30 items about prevention of blood stream, urinary tract and respiratory infection, etc.

\section{Scoring System:}

The rating scale was graded as follows: done correctly (1) and incorrect (0).Total score of all practices were 30 grades. Total score represented $100 \%$ and high score is good practice.

Tool IV: Infection control teaching guideline:

Infection control measures were structured by the researcher based on nurses' needs, and the related current literature. The contents of the teaching guidelines included ten sessions for educational and training program.

\section{Tools for patient:}

It includes two parts:

1) Socio-demographic and medical data sheet.

2) Observational checklist.

Part I: Socio-demographic and Medical Data Sheet: It included such as age, gender, marital status, educational level, and residence, and occupation, monthly income. Medical data such as to assess past and present medical history of the patients, duration of illness and date of admission, etc........

Tool II: Observational Check List:

It was developed after review the literature (Purohit, Verma, and Kalla,1998; Ndomba, Asteria, and Clara,2008; Kikuchi et al., 2003; and Church et al., 2006)and used by the researcher to assess sign and symptoms of infection through physical examination, laboratory investigation, and medical recorded.

It includes observation of 23 items divided into 5 main parts: sign and symptoms of infection at the site of burn (6 items), respiratory infection (4items), urinary tract infection (5 items), gastrointestinal disturbance (4 items) and blood stream infection (4 items). It answered by present or not present. Also, assess for laboratory investigation such as (WBCs) and vital signs. 


\section{Ethical considerations:}

An informed consent for participation in the study was taken verbally from study subjects after explanation of the purpose of the study. Individual involvement in the study was elective. Also privacy and confidentiality must be keepingfor all subjects' information.

\section{Validity and reliability:}

The questionnaires were ascertained by 7 experts from nursing and medical staff members to check the relevancy, clarity, comprehensiveness, and applicability of the questions. The test-retest scores present a value of 0.87. This questionnaires were translated from English into Arabic to assist the participant understand.

\section{Pilot study:}

A pilot study conducted on ten patient and ten nurses to test clearness, applicability and modification of the study instrument. Also, estimates the time needed to fill questionnaire was about 30-45 minutes. Participants inclusive in the pilot study were excluded from the master study sample.

\section{Field Work:}

- Once permission was granted from administer of hospital, the objective and process of the study was clarified for nurses and patients.

- $\quad$ Information collecting for this study was holed in the period from Nov. 2015 until March 2016.

- $\quad$ Patients in study were selected on post emergency stage (after stability of condition)

- The researcher collected the data during the morning and afternoon shifts in the burn unit at Public Fayoum Hospital, at two days each week.

- The patient and nurses assessment sheet was filled by the researcher through personal interview, within 3040 minutes, the purpose of the study was explained to subjects and a written approval to participate in the study was taken.

- $\quad$ Nurse knowledge questionnaire loaded by the researcher for two times (pre and posttest) for subjects for identified level of knowledge.

- Teaching program was carried out in 4 sessions. It consist oftwo sessions were given to cover knowledge about infection in the general and nosocomial infection and its prevention. Two sessions were given to cover guidelines about control of nosocomial infection, universal precautions. In addition to 2 sessions, to cover practical part of universal precaution.

- During each knowledge session the researcher utilized easy, concise and clear words. At the end of each session, a brief outline was given by the researcher, confirm the most important points included in each session. Before starting of each session, nurses were asked questions to remember the prescript given and to enhance the knowledge.

- Teaching nursing program was providing for the study group. It was preferred three days a week by the investigator. The teaching session was organized during morning.

- The observation checklist for signs and symptoms of infections in patients and nursing practice was loaded by the researcher for both studies within 20-30 minutes. Each patient observed 3 time pear day.

- Infection control teaching guidelines booklet was given to each nurse in the study group to support teaching and practicing.

- $\quad$ Subjects were approached by the researcher to assess nurse's knowledge related to nosocomial infection after implementing program sessions and evaluation of nurse performance once immediately after finishing the program to evaluate the impact of implementing infection control guidelines on nurse's performance andmonitoring signs and symptoms of infection among patients.

\section{Limitation of study:}

- $\quad$ These findings cannot be generalized because the little sample and elected from one geographical area.

- $\quad$ The scope of the study not used control group.

Data analysis:

Calculating the datawas carried by the Statistical Package for Social Sciences (SPSS). The collected data wereoffered using frequency and percentage, means and standard deviations.Also $x^{2}$ test were used for comparison within group. Pearson's correlation coefficient was used to test correlation between variables. Also , $\mathrm{p}$-value $\leq 0.05$ were statistical significance and non-significant difference was considered at $\mathrm{P}>0.05$.

\section{Results}

Table 1.Shows that the demographic and job characteristic of nurses in the study sample. According to the table nearly half of nurses (51.42) were less 20 years. Regarding years of experience, nearly to thirds of nurses $(62.85 \%)$ had workingexperience more than one year. While more than third of nurses $(37.14 \%)$ had a work experience less than one year at burn unit. Also, the majority of nurses $(85.71 \%)$ were married. In 
addition, job description $(62.85 \%)$ had a nursing school diploma. While, the nearly one third of staff nursing $22.85 \%$ had a technical health institute.

Table 2. Shows more than half of studied subjects (57.5) were male. While (42.5\%) were female, and more than two third $(65.0 \%)$ of subjects were lived in rural area. Considering education, more than one third of the studied subjects $(27.5 \%)$ were illiterate. Regarding to occupation, more than one third $(35.0 \%)$ of the studied subjects were housewife and one fourth $(25 \%)$ are skilled worker. As regards income,the most of the studied subjects $(72.5 \%)$ were had not enough income, while $(27.5 \%)$ were enough income.

Figure 1. Illustrates more than one third (37.5\%) of studied subjects were in age group from 25-34 years. While less than fourth of subjects more than 45 years.

Table 3. Present the nurses total knowledge scores about nosocomial infections. It can be observed that the nurses had a mean total knowledge scores of $(69.89+7.46)$. The highest mean knowledge scores were obtained in relation to hand washing $(80.7+15.8)$. Conversely, the mean knowledge score was very low $(25.87+8.7)$ in relation to surgical wound infections. The significant mentioned above are illustrated graphically in figure 2.

Table 4. Shows there is highly statistically improvement of practice level from before to after implementation of nursing guidelines, at $(\mathrm{p} \leq 0.001)$. The significant mentioned above are illustrated graphically in figure 3 .

Table 5. Reveals that a statistically significant difference between studied subjects pre and post implementation of teaching guideline regarding sign and symptoms of infection including pain, inflammation and swelling, hotness, burning urination, skin irritation, gastrointestinal disturbance and increase $\mathrm{WBCs}$ at $(\mathrm{p} \leq$ $0.05)$.

Table 6. Represented that the correlation between nurse's knowledge and practice. There are no statically significant correlation between nurse's knowledge and practice.

Table7.Revealed that there are significant correlation between knowledge, practice with age pre and post assessment $(r=0.462$ and 0.315 at $\mathrm{p}<0$. 05). However there are no statistically significant relations between education, experience with knowledge and practice $(\mathrm{p}>.05)$.

\section{Discussion}

Nosocomial infection (NI) is infection that is contracted from the environment or staff of a healthcare facility. It has many adverse effects on both patients and health care workers, it represents an undue economic burden, which increases the costs, hospitalization rate and need for antimicrobial medications and adds significant morbidity, and mortality (Rothensal, Guzman, and Crinch, 2012). Nosocomial infections (NI) are common in burn patients due to low immunity, severe clinical condition and extended hospitalization and multiple invasive diagnostic and therapeutic procedures (Oncul et al., 2009\& Kumar et al., 2011). Effective infection prevention and control is central to providing high quality health care for patients and safe environment for closely scrutinizing the burn wound to detect early signs of infection in healthcare settings (Smeltzer and Bare, 2010).

The finding of the existing study exhibit thataround half of nurses' staff was in age group less than 25 years old, and the majority of them were diploma nurse and the most of them have experience at burn unit more than 3 years. These finding in agreement with study by El-Sayed1, Gomaa, and Abdel-Aziz (2015) presented that all the study sample were females with a diploma degree and with a mean age of (X \pm SD 36.60 \pm 7.53 ), $40 \%$ of them have 10-20 years of experience; followed by $35 \%$ with less than ten years of experience, while $25 \%$ have more than 20 years of experience $(\mathrm{X} \pm \mathrm{SD}=14.84 \pm 6.954)$

The current study shows that most of the study had satisfactory level of knowledge regarding nosocomial infection after implementing program. These results are assent with Ibrahim, Said \& Hamdy (2011), who pointed that the majority of their studied group had enough information about infection and prevention precaution. As well as study by Mussa and Abass, (2014) emphasized that training program about infection control measures to all members of staff lead to understand the infection control policy and procedure as well as to motivate them to adhere to it.

Knowledge is considered the backbone of the prevention of nosocomial infections Haidegger, Nagy, Lehotsky, and Szilagyi, (2011) and Malan, (2009). The goal of continuous education in nursing is to enhance knowledge to promote the quality of health care delivery to the patients. Education change perception, growing knowledge, and lead to changes work practice especially in vital areas such as burn injury.

The finding of the current study revealed that higher scores of nosocomial infection regard knowledge after implementation of the educational program. This agreement with the findings of Ibrahim et al., (2011) who found the majority of their studied group, had enough information about infection and prevention precaution. As well as study by Mussa and Abass, (2014) emphasized that training program about infection control measures to all members of staff lead to understand the infection control policy and procedure as well as 
to motivate them to adhere to it. These finding was supported by the study carried out byGalal, Labib, Abouelhamd (2014) showed that improvement in total score knowledge after implementation of program among the nursing staff. In the same line study by Soliman, (2013) who found that, only the minority of the studied nurses knew the definition of infection and carrier before receiving the educational program.

The present results revealed improvement in nurses practice level post program implementation nursing guidelines. These may be attributed that hand washing and following personal protective equipment's were essential in reducing their potential contribution to the incidence of healthcare-associated infections. These results congruous with the results of Mandal(2007) who stated improve knowledge and skill after implementation of educational interventionabout burn and infection control. These led to patient safety and promote good health status. Also, study carried out by Eskander, Morsy, \& Elfeky (2013) to assess nurses' knowledge and practice regarding infection control standard precautions. The study exposed thatmore than half $(57.1 \%)$ of participations had satisfying performance scale. On the same line Cherry, Brown, Bethell, Nea, and Shaw (2012) who stated that aworthyand sustained improvements in hand hygiene performance and compliance as well as reductions in HCAI after educational interventions. Also emphasized that general application of standard health precautions must be routinely used in burn unit.

As regard to sign and symptoms of infection, the current study revealed that there is a highly statistically significant difference between studied subjects pre and post implementation of nursing guideline regarding sign and symptoms of infection including pain, increase respiratory secretion, dry and wet cough, burning urination diarrhea, and skin irritation, abdominal disturbance ,fever, inflammation and swelling. These finding supported by Kerith andColleagues (2004)reported that $10 \%$ to $65 \%$ hold of nosocomial pneumonia in the intensive care unit, and mortality rates are $>25 \%$. AlsoGastmeier and Colleagues (2002)found that develop significant bacteriuria after $72 \mathrm{~h}$ of urinary catheter insertion from prolonged catheterization. Bakke (2010) revealed that a significant endogenous Gram-negative bacteria (EGNB)from the patients' respiratory and gastrointestinal tract (GIT) within the first 24 to 48 hours after injury. In other study by Ahmed, Eshra, Nassar, \&El-Shikh (2000) revealed that a high incidence of nosocomial respiratory infections regarding the pseudomonas and was the causative agents in more than one fourth of the cases this results nurses' infection control practices were inadequate.

The present study revealed that a positive correlation between improvement of knowledge and practice post implementation of nursing guidelines. Which means that when knowledge of nurses using adequate information, demonstration and re-demonstration will be achievement nurses performance. These findings is supported by Rosenthal et al.,(2012) they found that the educational programs about the infection control precautions are significantly influenced the participants performance. Mohamed and Wafa (2011) stated that there was a positive significantly correlation between nurse's practice and knowledge pre and post implementation of infection control program.Also Zytone (2009)exhibited that highly a positive correlation was established between knowledge and practice through staff nurses.

The current study found that a statistically significant correlation between age, knowledge and practice among studied staff nurses. This may be assigned to efficacious and fresh knowledge. Whereas there was no statistically significant correlation between qualifications, experience with knowledge and practice of infection prevention and control (IPC). This supported by study byFayed et al., (2016) declared that continuing education regardless of age can significantly get better infection control practices and decrease rate of infection. Also there are a highly statistical significant difference between nurse's knowledge, practices and their socio demographic data (level of education and previous training).

\section{Conclusions}

The findings from this study revealed that nursing guidelines is highly effective in improving knowledge and practice for nurses regarding nosocomial infection in burn unit as well as patient outcome. There is statistically significant difference between studied subjects (patients) pre and post implementation of nursing guideline regarding sign and symptoms of infection including fever, pain, inflammation and swelling and respiratory infection. Based on these findings it is recommended to apply this intervention as a routine care for all staff nurses Also promoting patients and their relatives with Arabic guide regarding the burn damage, and how to prevent nosocomial infection for enhancing patients care in this area.

\section{Acknowledgements}

study.

I express my thankfulness towards all who have directly or indirectly helped me to accomplish this

\section{References}


Nursing Guidelines and Its Effects on Nurses' Knowledge and Patient Safety Regarding Nosocomial..

[1]. Ahmed, N., Eshra, D.M., Nassar, B.M., and El-Shikh, A.A. (2000). Study of nosocomial respiratory infections and nurses' performance related to infection control measures in artificially ventilated patients. Journal of Egypt Public Health Assoc.;75(12):199-217.

[2]. Ahmed, S A., Daef, E A., Badary, M S., Mahmoud, M A., And Abd-Elsayed, A A.,(2009): Nosocomial Blood Stream Infection in Intensive Care Units at Assiut University Hospitals (Upper Egypt) with Special Reference to Extended Spectrum B-Lactamase Producing Organisms. BMC Research Notes, 2:76 available at : http://www.biomedcentral.com/1756-0500/2/76

[3]. Bakke, C. K., (2010).Clinical and Cost Effectiveness of Guidelines to Prevent Intravascular Catheter-Related Infections in Patients on Hemodialysis. Nephrology Nursing Journal, 37(6), 601-616.

[4]. Burke, J. F., C. C. Bondoc, and W. C. Quinby. (1974). Primary burn excision and immediate grafting: a method shortening illness. J. Trauma14:389-395.

[5]. Canadian Council on Health Services Accreditation (CCHSA). (2005). CCHSA Patient safety goals - required organizational practice and evidence of compliance.

[6]. Cais, D., P., Turrini, R., N., and Strabelli, T., M., (2010).Infections inPatients Submitted to Hemodialysis: A Systematic Review. Rev Bras Ter Intensiva. 21(3):269-275.

[7]. Cherry, M., G., Brown, J., M., Bethell, G., Nea, T., and Shaw, N. Y., (2012).Features of Educational Interventions that Lead to Compliance with Hand Hygiene in Healthcare Professionals within A Hospital Care Setting. A BEME Systematic Review: BEME Guide No. 22. BEME Guide: Hand Hygiene Review, Pp406-420.

[8]. Church, D., Elsayed, S., Reid, O., Winston, B. and Lindsay, R. (2006). Burn wound infections. Clin Microbiol Rev. 19(2):40334.

[9]. Curtis, LT. (2008) .Prevention of Hospital Acquired Infection: Reviewof Non- Pharmacological Interventions. Journal of Hospital Infection; 69 (1): 204- 219

[10]. D'Souza AL, Nelson NG, McKenzie LB.(2009). Pediatric burn injuries treated in US emergency departments between 1990 and 2006. Pediatrics. Nov;124(5):1424-30.

[11]. El-Sayed, M.Z., Gomaa, M. and Abdel-Aziz, M. (2015). Nurses' Knowledge and Practice for Prevention of Infection in Burn Unit at a University Hospital: Suggested Nursing Guidelines. Journal of Nursing and Health Science, 4: 62-69.

[12]. Eskander, H., Morsy, W., and Elfeky, H. (2013). Intensive Care Nurses' Knowledge \& Practices regarding InfectionControl Standard Precautions at a Selected Egyptian Cancer Hospital. Journal of Education and Practice; 4 (19): 160 - 174.

[13]. Fayed, M.N., Hanan, T., Elbahnasawy, T.H., and Omar, KT.(2016). Effect of Instructional Program on Nurses Compliance with Universal Precautions of Infection Control. International Journal of Novel Research in Healthcare and Nursing, Vol. 3, Issue 1, pp: (81-92).

[14]. Galal, Y.S, Labib, J.R, and Abouelhamd, W.A. (2014). Impact of an infection-control program on nurses' knowledge and attitude in pediatric intensive care units at Cairo University hospitals.J Egypt Public Health Assoc. 2014 Apr;89(1):22-8

[15]. Gastmeier, P., Weigt, O. Sohr, D. and Ruden, H. (2002).Comparison of hospital-acquired infection rates in paediatric burn patients. J. Hosp. Infect. 52:161-165

[16]. Gill, C.J., and Gill, G.C. (2005).Nightingale in Scutari: her legacy reexamined. CID. Jun 15;40:1799-805.

[17]. Haidegger, T., Nagy, M., Lehotsky, A. ,Szilágyi, L. (2011).Digital imaging for the education of proper surgical hand disinfection. Lect Notes Comp Sci. 6893:619-626. doi: 10.1007/978-3-642-23626-6 76.

[18]. Hospenthal DR, Green AD, Crouch HK, et al.(2011).Infection control and prevention in deployed medical treatment facilities. $J$ Trauma. 2011; 71:S290-S298.

[19]. Ibrahim, Y.S., Said, A.M. and Hamdy, G.K. (2011). Assessment of infection control practices in neonatal intensive care unit. The Egyptian Journal of Community medicine, 29(4):27-45. 20.

[20]. Johnson, J.A.(2002). Nosocomial infections. Vet Clin North Am Small Anim Pract. 2002 Sep;32(5):1101-26.

[21]. Karim Rafla \& Edward E. Tredget (2011). Infection control in the burn unit. Burns; 37:5-15.

[22]. Kenetra ,C., (2013). Bloodstream Infections From Preexisting Intravenous Catheters. Dissertation Submitted in Partial Fulfillment of the Requirements for the Degree of Doctor of Philosophy Public Health Epidemiology Walden University. UMI, United State.

[23]. Keith, D. D., Garrett, K. M., Hickox,G., Echols, B. and Comeau, E.(2004). Ventilator-associated pneumonia: improved clinical outcomes. J. Nurs. Care Qual. 19:328-333

[24]. Kildal, M., Andersson, G. and Gerdin, B. (2002). Health status in Swedish burn patients Assessment utilizing three variants of the Burn Specific Health Sca Taylor, C., Lillis, C., and Lemon P. (2005). Philadelpia: Lippincott Williams \& Wilkins;. Fundamentals of Nursing the Art and Science of Nursing Care.

[25]. le. Burns. 28(7):639-45.

[26]. Kikuchi, H., Nishida, T., Kurokawa, M., Setoyama, M. and Kisanuki, A. (2003): Three cases of malignant melanoma arising on burn scars. J. Dermatol. 30(8):617-24

[27]. Kumar, A., Kashyap, B., Mishra, S., et al.(2011). Bacteriological analysis and antibacterial resistance pattern in burn sepsis: An observation at a tertiary care hospital in east Delhi. Infectious Diseases in Clinical Practice. 19:406-12.

[28]. Larson, E.L. (1999). Home hygiene: a reemerging issue for the new millennium. Am J Infect Control 1999 Dec 1;27:S1-S3.

[29]. Lewis, D., Heitkemper, N.\&Bucher, A. (2014). Medical surgical nursing: Assessment and management of clinical problems.9 th Ed. Philadelphia: Mosby \&Elsevier: 483-507.

[30]. Malan, K., (2009).Registered Nurses' Knowledge of Infection Control and Sterile Technique Principles in the Operating Room Complex of Private Hospitals Master Thesis. Faculty of Health Since, Nelson Mandela Metropolitan University; PP. 47 - 49.

[31]. Mandal, A.(2007). Role of topical negative pressure in pressure ulcer management. Journal of Wound Care;16:33-5.

[32]. Mohamed, S. A., and Wafa, A. M., (2011). The Effect of An Educational Program on Nurses Knowledge and Practice Related to HepatitisC Virus: A Pretest And Posttest Quasi-Experimental Design Australian Journal of Basic and Applied Sciences, 5(11):564570, 2011 ISSN 1991-8178.

[33]. Mussa, Y., M. \& Abass, K., S. (2014). Assessment of Nurses Knowledge Regarding Nursing Care for Patients with Burn. Journal of Natural Sciences Research. Vol.4, No.7. World J Crit Care Med. Aug 4, 2012; 1(4): 94-101.

[34]. Ndomba, A. and Clara, L.M.(2008).Preventing ICU infections in Tanzanian patients; nurses' knowledge, clinical practice and patients' views. International Journal of Urological Nursing, Volume 2, Number 1 March, pp33-41(9).

[35]. Oncul, O., Ulkur, E., Acar, E., et al.(2009). Prospective analysis of nosocomial infections in Burn Care Unit, Turkey. Indian J Med Res. 130:758-64.

[36]. Page CP et al. (1993). Antimicrobial prophylaxis for surgical wounds: Guidelines for clinical care. Arch Surg 1993, 128:79-88.

[37]. Plowman R, Graves N, Griffin MAS, Roberts JA, Swan AV, Cookson B, et al.(2001). The rate and cost of hospital-acquired infections occuring in patients admitted to selected specialties of a district general hospital in England and the national burden imposed. J Hosp Infect 2001;47:198-209. 
[38]. Purohit, A., Verma, G., and Kalla, S.(1998).Critical care nurses' knowledge in preventing nosocomial pneumonia. J. infect control, 12:697. Available at: http://gateway.nlm.nih.gov/Meeting

[39]. Rosenthal,V., Guzman, S. and Safdar,N.(2012). Reduction In Nosocomial Infection With Improved Hand Hygiene in Intensive Care Units of A Tertiary Care Hospital in Argentina, American Journal of Infection Prevention, 33(7), 2012, $392-397$.

[40]. Rothensal, V.D., Guzman, S., and Crinch, C.,( 2012):Device-Associated Nosocomial Infection Rates in Intensive Care Units of Argentina. Infection Hospital Epidemiology. 25(3):251-5.

[41]. Smeltzer, S., C., Bare, B., G., Hinkle, J., L., and Cheever, K., H., (2010). Brunner \& Sauddarth's Text Book of Medical Surgical Nursing.12th ed., volume (1). Philadelphia Lippincott, William \& Wilkins. New York. London, Buenos Aires, Hong Kong. Pp: $11381-11388$.

[42]. Smeltzer, S. and Bare, B. (2004). Brunner \& Suddarth's Textbook of Medical-Surgical Nursing. 10 ${ }^{\text {th }}$ ed.Philadelphia. Lippincott. P.159-165.

[43]. Soliman, R., A., Abd Elaziz, M., and El lawindi, M., (3013).Evaluationof an Isolation Program of Hepatitis C Virus Infected Hemodialysis Patients in Some Hemodialysis Centers in Egypt. ISRN Nephrology, Volume (2013), Article ID 395467,5 pages.

[44]. Szucs, M., Dencs, G., Varga, E., Balajcza, B., Kiss, G., Reuter, G., Csiky, B., Sandor, J., and Takacs, M., (2014): An Archived Serum Sample As a Clue for Identifying the Primary Source of A Nosocomial Hepatitis C Virus Outbreak in a Haemodialysis Unit. Arch Virol. 159:2207-2212.

[45]. Taylor, C., Lillis, C., and Lemon P. (2005). Philadelpia: Lippincott Williams \& Wilkins;. Fundamentals of Nursing the Art and Science of Nursing Care.

[46]. Weekes, LM., and Brooks, C. (1996). Drugs and therapeutic committees in Australia: Expected and actual performance. Brit $J$ Clin Pharmacol, 1996, 42:551-557.

[47]. Wenzel, R. P., and M. B. Edmond.(2001). The impact of hospital-acquired bloodstream infections. Emerg. Infect. Dis.7:174-177

[48]. Weinstein, RA. (2001).Controlling antimicrobial resitance in hospitals: Infection control and use of antibiotics. Emerg Infect Dis 2001 Mar;7(2):188-92.

[49]. Zytone, H., (2009).Effect of Training Program on Nurses Knowledge and Performance Related to Nursing Care of Post-Operative Open Heart Patients in ICU at Zagazig University Hospital. Unpublished Doctorate Dissertation, Faculty of Nursing ,Zagazig University, Egypt. Pp.124-29.

\section{Results:}

Table 1. Sociodemographic and characteristics of the sample $(\mathrm{N}=35)$ 
Nursing Guidelines and Its Effects on Nurses' Knowledge and Patient Safety Regarding Nosocomial..

\begin{tabular}{|c|c|c|}
\hline Items & Number & Percentage \% \\
\hline \multicolumn{3}{|l|}{ Age (years): } \\
\hline - $<25$ & 18 & 51.42 \\
\hline - $\quad 25-35$ & 10 & 28.57 \\
\hline - $\quad>35$ years & 7 & 20 \\
\hline Mean \pm SD & \multicolumn{2}{|c|}{$30.87 \pm 5.59$} \\
\hline \multicolumn{3}{|l|}{ Marital status : } \\
\hline - $\quad$ Married & 30 & 85.71 \\
\hline - Notmarried & 5 & 14.28 \\
\hline \multicolumn{3}{|l|}{ Nursing experience: } \\
\hline - $\quad<3$ years & 13 & 37.14 \\
\hline - $3+$ & 22 & 62.85 \\
\hline \multicolumn{3}{|l|}{ Job description: } \\
\hline - Staff nurse & 22 & 62.85 \\
\hline - Technical nurse & 8 & 22.85 \\
\hline - Head nurse & 5 & 14.28 \\
\hline
\end{tabular}

Figure 1. Age distribution among patients study

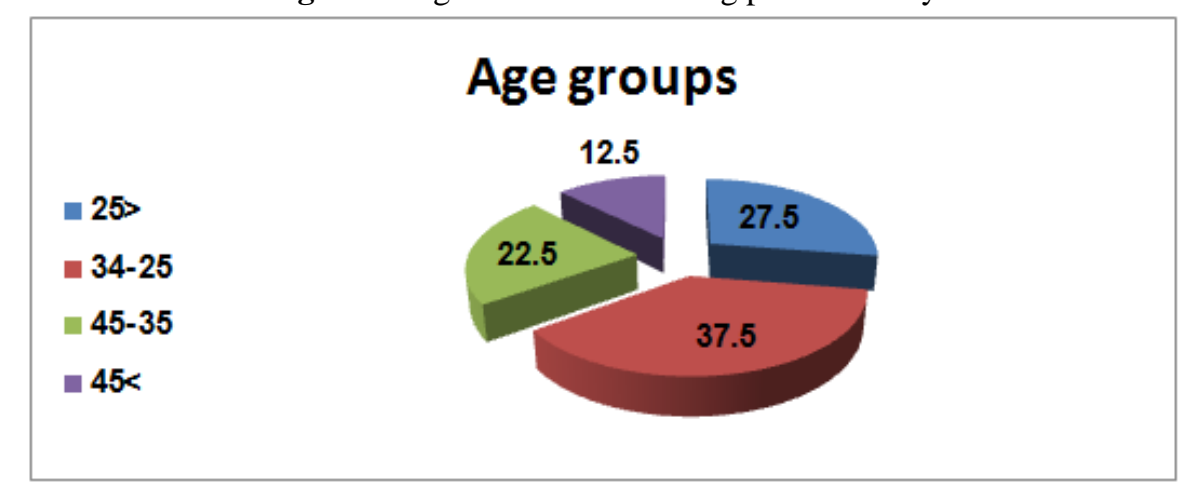

Table 2: Frequency and percentage distribution of the studied subjects (Patients) according to their sociodemographic characteristics $(\mathrm{N}=40)$

\begin{tabular}{|c|c|c|c|}
\hline \multicolumn{2}{|c|}{ Variables } & Number & Percentage \% \\
\hline \multicolumn{4}{|c|}{ Gender: } \\
\hline$\bullet$ & Male & 23 & 57.5 \\
\hline$\bullet$ & Female & 17 & 42.5 \\
\hline \multicolumn{4}{|c|}{ Marital status: } \\
\hline$\bullet$ & Single & 4 & 10 \\
\hline$\bullet$ & Married & 34 & 85 \\
\hline$\bullet$ & Widow & 2 & 5 \\
\hline \multicolumn{4}{|c|}{ Level of education: } \\
\hline$\bullet$ & University & 5 & 12.5 \\
\hline$\bullet$ & Basic qualification & 5 & 12.5 \\
\hline$\bullet$ & Secondary & 13 & 32.5 \\
\hline$\bullet$ & Read and write & 6 & 15 \\
\hline$\bullet$ & Illiterate & 11 & 27.5 \\
\hline \multicolumn{4}{|c|}{ Occupation: } \\
\hline$\bullet$ & Employer & 6 & 15 \\
\hline$\bullet$ & Skilled worker & 10 & 25 \\
\hline$\bullet$ & Farmer & 7 & 17.5 \\
\hline$\bullet$ & House wife & 14 & 35 \\
\hline$\bullet$ & Not working & 3 & 7.5 \\
\hline \multicolumn{4}{|c|}{ Residence: } \\
\hline$\bullet$ & Urban & 26 & 65 \\
\hline$\bullet$ & Rural & 14 & 35 \\
\hline \multicolumn{4}{|c|}{ Income: } \\
\hline$\bullet$ & Not Enough & 29 & 72.5 \\
\hline$\bullet$ & Enough & 11 & 27.5 \\
\hline
\end{tabular}

Table 3. Difference between pre-test and post-test scores of knowledge for the study group \begin{tabular}{|l|l|l|l|l|}
\hline Knowledge items & Pre test & Post test & T- test & P value \\
\hline
\end{tabular}

DOI: 0.9790/1959-0505040616 $\quad$ www.iosrjournals.org $\quad 14 \mid$ Page


Nursing Guidelines and Its Effects on Nurses' Knowledge and Patient Safety Regarding Nosocomial..

\begin{tabular}{|ll|l|l|l|l|}
\hline & \multicolumn{1}{r|}{ Mean \pm S.D } & \multicolumn{1}{r|}{ Mean \pm S.D } & & \\
\hline$\bullet$ & Infection & $12.12 \pm 12.34$ & $18.12 \pm 12.34$ & 9.47 & $\mathrm{P}<0.01$ \\
\hline$\bullet$ & Nosocomial infections & $11.0 \pm 9.8$ & $13.5 \pm 9.8$ & 5.98 & $\mathrm{P}<0.01$ \\
\hline$\bullet$ & Sterilization & $20.2 \pm 9.44$ & $29.2 \pm 10.44$ & 12.48 & $\mathrm{P}<0.001$ \\
\hline$\bullet$ & Hand washing & $21.7 \pm 15.8$ & $30.7 \pm 15.8$ & 5.59 & $\mathrm{P}<0.01$ \\
\hline$\bullet$ & Urinary tract infections & $10.45 \pm 10.87$ & $11.23 \pm 10.87$ & 12.10 & $\mathrm{P}<0.05$ \\
\hline$\bullet$ & Respiratory infection & $9.03 \pm 13.3$ & $14.03 \pm 13.3$ & 5.87 & $\mathrm{P}<0.01$ \\
\hline$\bullet$ & Blood stream infections & $8.23 \pm 11.8$ & $14.23 \pm 11.8$ & 5.18 & $\mathrm{P}<0.01$ \\
\hline$\bullet$ & Surgical wound infections & $14.87 \pm 8.7$ & $23.87 \pm 8.7$ & 9.48 & $\mathrm{P}<0.001$ \\
\hline Total knowledge & $69.89 \pm 9.46$ & $89.96 \pm 7.46$ & 12.48 & $\mathrm{P}<0.001$ \\
\hline
\end{tabular}

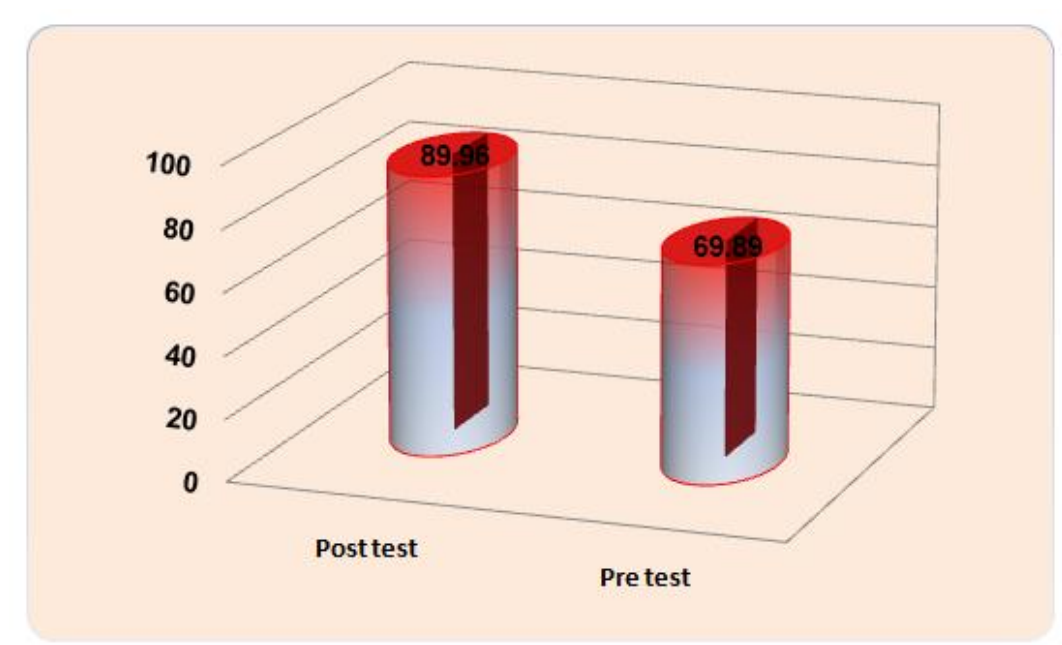

Figure 2: Percent Distribution of nurses' knowledge

Table 4. Total nurse practice scores related to prevention of infection

\begin{tabular}{|l|l|c|c|c|}
\hline Procedure & & Pre implementation & Post implementation & P value \\
\hline \multirow{3}{*}{ Hand washing } & Correct & 20 & 30 & 0.001 \\
\cline { 2 - 5 } & incorrect & 15 & 5 & 0.001 \\
\hline \multirow{3}{*}{ Wear protective cloth } & Correct & 14 & 29 & 0.001 \\
\cline { 2 - 5 } & Incorrect & 21 & 6 & 0.001 \\
\hline Use aseptic technique & Correct & 9 & 28 & 0.001 \\
\cline { 2 - 5 } & Incorrect & 26 & 7 & 0.001 \\
\hline Proper environment control & Correct & 5 & 32 & 0.001 \\
\cline { 2 - 5 } & Incorrect & 30 & 3 & 0.001 \\
\hline
\end{tabular}

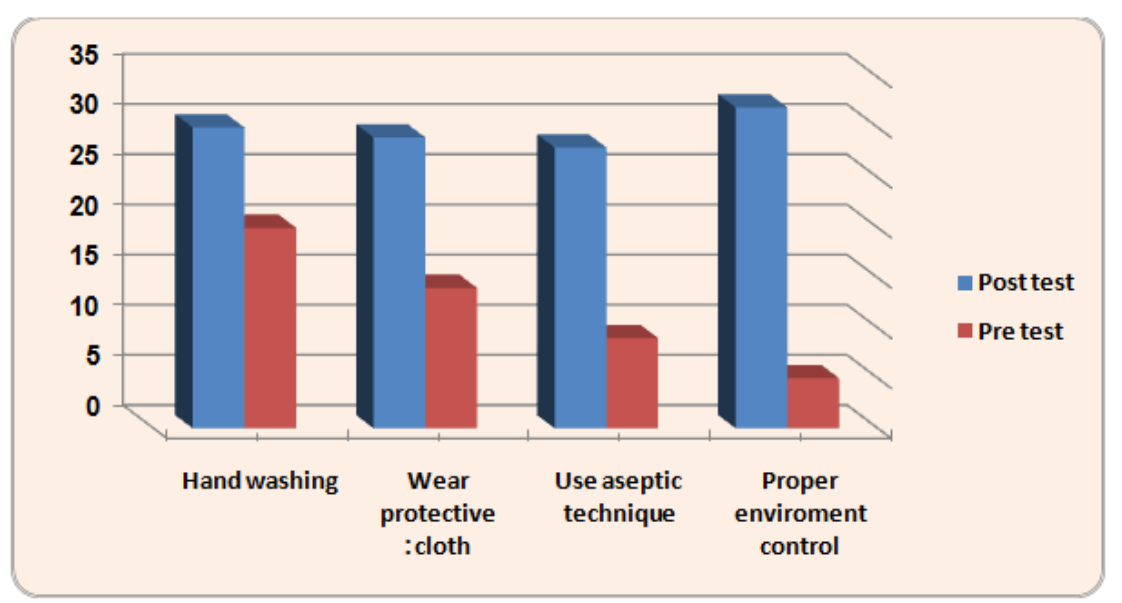

Figure 3. Percentage distribution of practice level among nurses

Table 5.Frequency distribution of studied subjects regarding to signs and symptoms of infection pre and post implementation of program $(\mathrm{N}=40)$ 
Nursing Guidelines and Its Effects on Nurses' Knowledge and Patient Safety Regarding Nosocomial..

\begin{tabular}{|c|c|c|c|c|c|c|}
\hline \multicolumn{2}{|c|}{ Signs and symptoms of infection } & \multicolumn{2}{|c|}{$\begin{array}{c}\text { Pre } \\
\text { implementation }\end{array}$} & \multicolumn{2}{|c|}{ Post implementation } & \multirow[t]{2}{*}{ Pvalue } \\
\hline & & $\mathbf{N}$ & $\%$ & $\mathbf{N}$ & $\%$ & \\
\hline \multirow[t]{2}{*}{ Fever } & No & 30 & 75 & 38 & 95 & \multirow[t]{2}{*}{$0.058^{*}$} \\
\hline & Yes & 10 & 25 & 2 & 5 & \\
\hline \multirow[t]{2}{*}{ Redness. } & No & 20 & 50 & 32 & 80 & \multirow[t]{2}{*}{0.051} \\
\hline & Yes & 20 & 50 & 8 & 20 & \\
\hline \multirow[t]{2}{*}{ Inflammation and Swelling } & No & 21 & 52.5 & 30 & 75 & \multirow[t]{2}{*}{0.048} \\
\hline & Yes & 19 & 47.5 & 10 & 25 & \\
\hline \multirow[t]{2}{*}{ Skin irritation } & No & 32 & 80 & 35 & 87.5 & \multirow[t]{2}{*}{0.046} \\
\hline & Yes & 8 & 20 & 5 & 12.5 & \\
\hline \multirow{2}{*}{ Hotness } & No & 30 & 75 & 36 & 90 & \multirow[t]{2}{*}{0.047} \\
\hline & Yes & 10 & 25 & 4 & 10 & \\
\hline \multirow[t]{2}{*}{ Pain } & No & 28 & 70 & 31 & 77.5 & \multirow[t]{2}{*}{0.041} \\
\hline & Yes & 12 & 30 & 9 & 22.5 & \\
\hline \multirow[t]{2}{*}{ Infection with dressing } & No & 37 & 90.25 & 38 & 95 & \multirow[t]{2}{*}{0.63} \\
\hline & Yes & 3 & 7.5 & 2 & 5 & \\
\hline \multirow[t]{2}{*}{ Respiratory infection } & No & 33 & 82.5 & 37 & 92.5 & \multirow[t]{2}{*}{0.052} \\
\hline & Yes & 7 & 17.5 & 3 & 7.5 & \\
\hline \multirow[t]{2}{*}{ Dry or wet cough } & No & 32 & 80 & 37 & 92.5 & \multirow[t]{2}{*}{0.058} \\
\hline & Yes & 8 & 20 & 3 & 7.5 & \\
\hline \multirow[t]{2}{*}{ Burning during urination } & No & 30 & 75 & 34 & 85 & \multirow[t]{2}{*}{0.046} \\
\hline & Yes & 10 & 25 & 6 & 15 & \\
\hline \multirow[t]{2}{*}{ Gastrointestinal disturbances } & No & 26 & 65 & 37 & 92.5 & \multirow[t]{2}{*}{0.038} \\
\hline & Yes & 14 & 35 & 3 & 7.5 & \\
\hline \multirow[t]{2}{*}{ Increase WBCs } & No & 29 & 72.5 & 34 & 85 & \multirow[t]{2}{*}{0.045} \\
\hline & Yes & 11 & 27.5 & 6 & 15 & \\
\hline
\end{tabular}

Table 6. Correlation between total nurse's knowledge and practice

\begin{tabular}{|l|c|c|}
\hline \multicolumn{2}{|c|}{ Items } & \multicolumn{2}{|c|}{ Practice score } \\
\hline Knowledge & $R$ & $p$-value \\
\cline { 2 - 3 } & 0.54 & $>0.05$ \\
\hline
\end{tabular}

Table 7.Correlations between socio demographic data and patients' knowledge and practice pre, post the implementation program $(\mathrm{N}=40)$.

\begin{tabular}{|l|c|c|c|c|}
\hline \multirow{3}{*}{ Items } & \multicolumn{2}{|c|}{ Knowledge } & \multicolumn{2}{c|}{ Practice } \\
\cline { 2 - 5 } & Before & After & Before & After \\
\cline { 2 - 5 } & $\mathrm{P}(\mathrm{R})$ & $\mathrm{P}(\mathrm{R})$ & $\mathrm{P}(\mathrm{R})$ & $\mathrm{P}(\mathrm{R})$ \\
\hline Age & $0.651(>.05)$ & $0.462(<.05)$ & $0.228(>.05)$ & $0.315(<.05)$ \\
\hline Education & $0.217(>.05)$ & $0.431(>.05)$ & $0.540(>.05)$ & $1.483(>.05)$ \\
\hline Experience & $0.421(>.05)$ & $0.572(>.05)$ & $1.062(>.05)$ & $0.431(>.05)$ \\
\hline
\end{tabular}

*p<0.05: significant 